\title{
Risk factors for acquisition of scrub typhus in children admitted to a tertiary centre and its surrounding districts in South India: a case control study
}

Winsley Rose ${ }^{1 *}$, Gagandeep Kang ${ }^{2,6}$, Valsan Philip Verghese ${ }^{1}$, Sadanandane Candassamy ${ }^{3}$, Prasanna Samuel ${ }^{4}$, John Jude Antony Prakash ${ }^{5}$ and Jayaprakash Muliyil ${ }^{2}$

\begin{abstract}
Background: Scrub typhus is a mite borne zoonosis common in the tropics with no good preventive strategy. Children are also affected leading to considerable morbidity and mortality. We conducted a case control study and a vector survey to determine the risk factors for acquisition of scrub typhus.

Methods: A case control study with a 1:2 case control ratio was conducted over a 2 year period at a tertiary care centre and its surrounding districts in South India. Cases were children $<15$ years with confirmed scrub typhus. Controls were age and locality matched community controls without fever. Demographic, environmental and behavioural risk factors were obtained in cases and controls by an interview and an environmental survey. A vector survey was also undertaken in the immediate vicinity of the cases.
\end{abstract}

Results: Case Control study: 101 cases and 167 controls were analysed. On multivariate analysis, significant association was observed with environmental factors such as the presence of a water body within $100 \mathrm{~m}$ of the house (OR 3.56(1.36,9.75); p 0.011), cooking outside the house (OR 5.61 (1.51,23.01); p 0.011), owning pets (OR 3.33(1.16,9.09); p $0.031)$, and the presence of bushes within $5 \mathrm{~m}$ of the house (OR $2.78(1.11,7.69) ; \mathrm{p} 0.033)$. Of the behavioural factors, the child going to school by a vehicle (OR $3.12(2.29,8.37) ;$ p 0.006) was associated with an increased risk. Drying clothes on a clothesline showed a trend towards protection from acquiring scrub typhus (OR $0.31(0.08,1.08) ; \mathrm{p} 0.077)$. Vector survey:26 rodents were trapped in as many houses. Trombiculid mites were isolated in 24 houses with 9(34.6\%) being able to transmit scrub typhus. 254 trombiculid mites belonging to four species and two genera were collected. Leptotrombidium deliense, (33.5\%). Schoengastiella ligula, (11.0\%) of the total mite specimens collected. S. ligula always co-existed with $L$. deliense. The estimated Chigger index for Leptotrombidium deliense and Schoengastiella ligula was 3.27and 1.08 per animal respectively.

Conclusions: Our study highlights risk factors for scrub typhus, some of which may be modifiable. A clean peridomestic environment free of vegetation, drying clothes on a clothesline and cooking indoors may decrease the risk of scrub typhus.

Keywords: Scrub typhus, Children, Risk factors, Mites

\footnotetext{
* Correspondence: winsleyrose@cmcvellore.ac.in

'Department of Pediatrics, Christian Medical College, Vellore, Tamil Nadu,

India

Full list of author information is available at the end of the article
}

(c) The Author(s). 2019 Open Access This article is distributed under the terms of the Creative Commons Attribution 4.0 International License (http://creativecommons.org/licenses/by/4.0/), which permits unrestricted use, distribution, and reproduction in any medium, provided you give appropriate credit to the original author(s) and the source, provide a link to the Creative Commons license, and indicate if changes were made. The Creative Commons Public Domain Dedication waiver (http://creativecommons.org/publicdomain/zero/1.0/) applies to the data made available in this article, unless otherwise stated. 


\section{Author summary}

Scrub Typhus is a re-emerging illness in the tropics with considerable morbidity and mortality. It is transmitted by mites to humans. A clear understanding of the risk factors for acquiring scrub typhus is essential to formulate preventive strategies. Our study was done to determine environmental and behavioural risk factors for acquiring scrub typhus in children. We compared children who had scrub typhus with age and locality matched children who did not have scrub typhus. We augmented our study with a vector survey by isolating mites from rodents around the homes of the children who had scrub typhus. In our analysis, we found certain environmental and behavioural factors that were associated with an increased risk and also found some factors which were protective. Our vector survey found that the mites capable of transmitting scrub typhus were found in and around the homes of the children who had scrub typhus. The details are presented and discussed in the study.

\section{Background}

Scrub typhus is a mite borne zoonosis endemic in the socalled tsutsugamushi triangle with an estimated 1 billion people at risk and about 1 million cases occurring annually [1]. The disease is becoming increasingly wide spread with cases being recently reported from Africa, South America and the Middle East [2-4]. A distinct seasonality is noted with the disease occurring in the cooler months in South India [5]. Affected children usually present as a non-specific febrile illness with a typical eschar being present in about $40 \%$ of them [6]. Severe forms of the disease presenting as encephalitis with considerable mortality have also been described in children [7]. Delayed diagnosis due to the nonspecific presentation, low index of suspicion and lack of availability of diagnostic tests results in significant morbidity and mortality [1, 8]. Antibiotic treatment has been shown to be effective in treating scrub typhus [9].

Scrub typhus is caused by Orientia tsutsugamushi, a gram negative intracellular pathogen. It is transmitted by the larval stage (chigger) of the trombiculid mite, usually of the genus Leptotrombidium. The mites are invisible to the naked eye and have a four-stage lifecycle: egg, larva, nymph and adult. The chigger needs a mammalian tissue meal to develop into the nymph. Only the bite of an infected chigger transmits disease. The other stages are free living in the soil $[10,11]$. The bite leaves a characteristic black eschar that is useful for diagnosis, when found [12]. The mites act as the vector and the primary reservoirs for O.tsutsugamushi [13]. Once infected by feeding on the body fluid of mammals, they maintain the infection throughout their life stages by transovarial transmission and transtadial transmission [14]. Chigger mite populations can hence autonomously maintain their infectivity over long periods of time.

Scrub typhus is transmitted only by vectors and not from person to person. Therefore, an assessment of exposure to the infectious agent in order to determine the level of exposure in a setting and the risk of acquisition of disease over time is vital in understanding the disease. In addition, at the household level, determination of the modifiable environmental and behavioural factors that put a person at risk of contact with the vector and disease would aid the formulation of possible interventional strategies. Previous studies in adults have shown environmental and behavioural risk factors for acquiring scrub typhus with the highest risk in farm workers, those working in vegetable fields and hilly areas, and harvesting in autumn [15-17]. Children have limited mobility and different behavioural patterns and there are no similar studies in children. Hence, we performed a community based case control study to ascertain risk factors for acquisition of scrub typhus in children. We also conducted a vector survey on rodents captured from the vicinity of the houses of children with scrub typhus disease to determine the likely areas where children may have acquired their disease.

\section{Methods \\ Case control study}

The study period spanned 2 years from January 2015 to December 2016. Cases were children aged less than 15 years diagnosed to have scrub typhus at the Christian Medical College, Vellore (CMC) based on a positive InBiosScrub Typhus Detect ${ }^{\text {tw }}$ IgM ELISA test (Inbios International Inc., Seattle, WA, USA) performed and interpreted as described previously [18]. Cases were included in the study if they resided within an $80 \mathrm{~km}$ radius of $\mathrm{CMC}$ and provided informed consent. Two age (+/ 1 year) and locality matched healthy controls were chosen for each case within a month of case recruitment. Age matching was done so that differences in behavioural patterns between ages are minimized. Location matching was done so that effect of differences in the macro-environment are negated. The house of the case was visited and closest street junction to the case's house identified. A random number between 01 and 59 was then obtained to choose the control. The first digit denoted the direction of the street to be selected or a field hut (0-North, 1-East, 2-South, 3- West and 5- field hut). The second digit denoted the number of houses to be skipped in the chosen direction or the number of field huts to be skipped to choose a control. An age matched healthy control was then identified and chosen to take part in the study after obtaining informed consent. The same exercise was repeated to choose the second control. A recording form which included demographic, environmental and behavioural data was filled for both cases and controls. The recording form was filled by administering a questionnaire to a parent of the case or control and supplemented by a visual survey of the surroundings. Each control also had a blood sampling done for Scrub Typhus IgM and IgG to look for past or asymptomatic scrub typhus. All cases and controls houses 
were Geographic Information System (GIS) coded and plotted on a map to assess clustering. Socio-economic status scoring was done using the revised Kuppuswamy's socioeconomic status scale [19].

The potential risk factors assessed were determined by a pilot survey undertaken by two of the investigators. Sample size was calculated for a case to control ratio of $1: 2$ with the background exposure in controls expected to be $15 \%$, to detect a factor with an odds ratio of 2 for cases with a $5 \%$ probability of type I error and $80 \%$ power. Ninety seven cases and 194 controls were needed.

Statistical analysis Analysis of data was performed using statistical software STATA version 13.1 (StataCorp, College Station, Texas, USA). As a first step, we excluded all controls who were either positive for scrub typhus IgM or IgG to ensure inclusion of only eligible controls. We used descriptive statistical methods (means, medians quartiles, standard deviations, frequencies and percentages)_to summarize all study variables. Secondly, we compared the distribution of environmental, behavioural and socio-demographic risk factors between cases and controls using chi-square or fisher's exact tests, as appropriate. Finally, all factors with $P \leq 0.1$ in the bi-variate analyses and other known prior risk factors were considered for inclusion in the multi-variable logistic regression analysis to identify independent risk factors for scrub typhus. Results from multivariable logistic regression analysis were presented as odds ratios with $95 \%$ confidence intervals (CI).

\section{Vector survey}

The houses of all the cases in the case control study were visited by a field worker. Rodents and shrews were captured using Sherman traps of the size $3 " \times 3 " \times 10$ " (W x H x L), designed for live capture of rats. The traps were baited with fried coconut. The traps were placed one hour before sunset and collected the next day morning. In each of the cases' houses, 2 or 3 traps were placed inside and just around the houses. Once the rodent was trapped, the rodent was placed in a glass desiccator and a glass lid placed over the desiccator. Only one rodent was placed at a time in the desiccator. A single piece of unspun cotton was dipped in chloroform and then placed inside the glass desiccator. The animal is observed for cessation of voluntary movement and recumbency. A deep plane of anaesthesia was indicated by the lack of righting reflex when the container was tipped slightly and the respiratory rate was reduced to about $50 \%$ of the pre-anaesthetic rate $(80-100$ breaths/min). This usually happened in about $1 \mathrm{~min}$ in mice and $2 \mathrm{~min}$ in rats. If at any time the rodent had difficulty breathing (respiration becomes laboured, slows or stops), the desiccator was immediately opened and the rodent removed. Once the rodent was in deep plane of anaesthesia, it was removed from the desiccator and the animal's mucous membrane colour, respiratory rate and withdrawal reflexes are checked. A noxious stimulus (toe pinch) was applied and if the animal responded to the toe pinch, it was returned to the desiccator for another $30 \mathrm{~s}$. If the mucous membrane colour and respirations were normal and its withdrawal reflexes were absent, the rodent was ready for the mite collection. The ears and inter-digital spaces were swabbed with cotton tipped ear buds and the mite chiggers collected in an eppendorf tube with $70 \%$ alcohol. The hair was then combed on to a plastic tray and the mites collected in another eppendorf tube. If the rodents were trapped inside houses, they were released outside the house in the wild and if they were trapped outside, they were released back in the same place. Within a few minutes, the rodents were able to regain consciousness and run away. The eppendorf tubes were transported to the laboratory for identification of the mites and further testing. Mites were mounted in Hoyers medium, examined under the microscope and identified up to species level using standard taxonomical keys [20]. The chigger index (average number of chiggers per rodent) was estimated [21].

\section{Ethics statement}

Ethics committee approval was obtained from the Institutional Review Board (Registration Number: ECR/326/ INST/TN/2013 issued under Rule 122D of the Drugs \& Cosmetics Rule 1945, Govt. of India) of Christian Medical College, Vellore to conduct the study. Institutional Animal Ethics Committee (IAEC) of the Christian Medical College, Vellore (Registration number: 88/PO/RcBi/SL/1999/ CPCSEA registered with Committee for the Purpose of Control And Supervision of Experiments on Animals (CPCSEA), Ministry of Environment, Forests and Climate Change, Government of India) approval was also obtained for trapping of rodents to obtain mite chiggers. Written informed consent was obtained from a parent/guardian of all children who were enrolled in the study. Written assent was obtained from all children above the age of 8 years in addition to the parent/guardian consent. The rodents and shrews were captured using traps and anaesthetized to obtain mites from them. All rodents and shrews were released back in the same environment after obtaining the mites.

\section{Results}

There were 113 cases and 226 controls recruited in the study. Twelve cases and 59 controls were excluded from analysis. The main reasons for exclusion were scrub typhus IgM/IgG positivity in the controls, and loss of samples in the laboratory (11 cases and their corresponding 22 controls) as shown in Fig. 1. In all 101 cases and 167 controls were used in the final analysis.

All the cases belonged to three administrative districts viz., Chittoor district in Andhra Pradesh and Vellore and Tiruvannamalai districts in Tamil Nadu. The baseline demographic data of cases and controls are given in Table 1. 



Fig. 1 Flow chart of cases and controls recruited

Many demographic, environmental and behavioural factors that were evaluated by matched pair analysis as shown in Table 2. Factors associated with a significant risk of scrub typhus on univariate analysis were the following: belonging to a middle or high socio-economic stratum, father having a skilled occupation, the presence of a water body within $100 \mathrm{~m}$ of the house in the form of irrigation canals or small lakes, living in a house with plastered walls, living in a house with more than 2 rooms, having furniture to sit and cots for sleeping, having piped drain for sullage, having a toilet, storing agricultural produce in the house, owning a pet, presence of bushes within $5 \mathrm{~m}$ of the house, using sitting on furniture, usually sleeping on a cot, and going to school by a vehicle. The only protective factor on univariate analysis was the child usually playing outside the house. On multivariate analysis including all factors with a $p<$ 0.1 , the only variables that were associated with significant risk were the presence of a water body within 100 $\mathrm{m}$ of the house (OR 3.56(1.36,9.75); p 0.011), cooking outside the house (OR 5.61 (1.51,23.01); p 0.011), owning pets (OR 3.33(1.16,9.09); p 0.031), the presence of bushes within $5 \mathrm{~m}$ of the house (OR 2.78 (1.11,7.69); p $0.033)$ and going to school by a vehicle (OR 3.12 (2.29, 8.37); p 0.006). Drying clothes on a clothesline showed a trend towards protection from acquiring scrub typhus (OR 0.31 (0.08, 1.08); p 0.077).

Rodents were trapped in and around 26 of the cases' houses. Trombiculid mites (Figs. 2 and 3) were isolated in 24 of them. Trombiculid mites capable of transmitting

Table 1 Baseline demographic data of cases and controls

\begin{tabular}{lll}
\hline & Cases (\%) & Controls (\%) \\
& N 101 & N 167 \\
\hline Age $<5$ years & $50(49.5)$ & $81(48.5)$ \\
Male & $59(58.4)$ & $104(62.3)$ \\
Father's occupation - skilled & $42(41.6)$ & $39(23.4)$ \\
Highest family education atleast high school & $74(73.3)$ & $107(64.1)$ \\
Socio-economic status - middle or high & $41(40.6)$ & $38(22.8)$ \\
\hline
\end{tabular}

scrub typhus were isolated in $9(34.6 \%)$ of the houses where the rodents were trapped. A total of 254 trombiculid mites belonging to four species and two genera was collected (Table 3). Leptotrombidium deliense, the major vector of scrub typhus pathogen [18] was the predominant species (33.5\%) next to Leptotrombidium insigne. Schoengastiella ligula, the secondary vector of scrub typhus [21] constituted $11.0 \%$ of the total mite specimens collected and the species was isolated in 4 (15.4\%). S. ligula always co-existed with $L$. deliense. The estimated Chigger index for Leptotrombidium deliense and Schoengastiella ligula was 3.27and 1.08 per animal respectively.

\section{Discussion}

Our study was conducted to determine demographic, environmental and behavioural risk factors for acquisition of scrub typhus in children. Similar studies have been done in adults, where the main risk factors were related to their occupation. Since occupation is not relevant and mobility is relatively restricted in children, our study brings out those risk factors which are related to the immediate environment where children live and their behaviour. Environmental factors seemed to be the most important in increasing the risk for scrub typhus compared to demographic and behavioural factors. The presence of a water body in the vicinity of the house, cooking outside the house, owning pets and the presence of scrub vegetation in the immediate surroundings of the house were all associated with an increased risk.

Of the environmental factors, the presence of a water body within $100 \mathrm{~m}$ of the house showed a 3.5 fold increase in the risk of scrub typhus. Small geographic regions which are high risk for humans to acquire scrub typhus include forest clearings, river banks and grassy regions. These regions which provide the optimal environment for the infected mites to thrive have been described as 'scrub typhus islands' [22]. It is likely that the presence of cases in the vicinity of a water body represents such an island. The presence of bushes in close 
Table 2 Univariate and multivariate analysis on demographic, environmental and behavioural factors associated with acquisition of scrub typhus

\begin{tabular}{|c|c|c|c|c|c|c|}
\hline \multirow[t]{2}{*}{ Variable } & \multicolumn{3}{|c|}{ Univariate Analysis } & \multicolumn{3}{|c|}{ Multivariate analysis } \\
\hline & $\mathrm{OR}$ & $95 \% \mathrm{Cl}$ & $p$-value & $\mathrm{OR}$ & $95 \% \mathrm{Cl}$ & $p$ \\
\hline \multicolumn{7}{|l|}{ Demographic Factors } \\
\hline Age group $<5$ years & 1.04 & $(0.64,1.71)$ & 0.874 & & & \\
\hline Sex- Male & 0.85 & $(0.51,1.41)$ & 0.531 & & & \\
\hline Father occupation - Skilled & 2.33 & $(1.37,4)$ & 0.002 & 1.25 & $(0.21,3125)$ & 0.663 \\
\hline Mother occupation - Skilled & 0.67 & $(0.38,1.16)$ & 0.157 & & & \\
\hline Highest family education -atleast high school & 1.54 & $(0.89,2.7)$ & 0.122 & & & \\
\hline Socio Economic Score - Middle or high & 2.32 & $(1.35,4)$ & 0.002 & 1.35 & $(0.45,3.57)$ & 0.546 \\
\hline \multicolumn{7}{|l|}{ Environmental Factors } \\
\hline Location of house - Adjoining field & 1.56 & $(0.91,2.7)$ & 0.109 & & & \\
\hline Road leading to house - Paved & 0.93 & $(0.55,1.56)$ & 0.773 & & & \\
\hline Presence of water body within $100 \mathrm{~m}$ & 2.65 & $(1.43,4.94)$ & 0.002 & 3.56 & $(1.36,9.75)$ & 0.011 \\
\hline Terraced house & 1.37 & $(0.79,2.38)$ & 0.254 & & & \\
\hline Cemented/tiled floor & 2.08 & $(0.56,7.75)$ & 0.275 & & & \\
\hline Plastered walls & 2.76 & $(1.01,7.57)$ & 0.048 & 8.03 & $(0.99,187.97)$ & 0.091 \\
\hline Concrete roof & 1.49 & $(0.86,2.6)$ & 0.157 & & & \\
\hline House with $>2$ rooms & 2.33 & $(1.41,3.87)$ & 0.001 & 1.18 & $(0.52,2.68)$ & 0.678 \\
\hline Furniture used for sitting & 1.83 & $(1.02,3.3)$ & 0.044 & 1.53 & $(0.55,4.43)$ & 0.413 \\
\hline Cot used for sleeping & 2.18 & $(1.28,3.73)$ & 0.004 & 1.52 & $(0.56,4.15)$ & 0.401 \\
\hline Paved surroundings & 1.43 & $(0.87,2.35)$ & 0.156 & & & \\
\hline Piped drain for sullage & 2.4 & $(1.32,4.35)$ & 0.004 & 1.22 & $(0.43,3.54)$ & 0.703 \\
\hline Cesspool around the house & 1.26 & $(0.51,3.11)$ & 0.611 & & & \\
\hline Cooking outside the house & 1.92 & $(0.95,3.86)$ & 0.068 & 5.61 & $(1.51,23.01)$ & 0.011 \\
\hline Gas used for cooking & 1.45 & $(0.78,2.7)$ & 0.239 & & & \\
\hline Toilet present & 1.75 & $(1.06,2.85)$ & 0.027 & 1.19 & $(0.42,3.33)$ & 0.731 \\
\hline Agricultural produce stored in house & 2.22 & $(1.22,4)$ & 0.008 & 1.2 & $(0.43,3.22)$ & 0.742 \\
\hline Stored firewood present & 0.97 & $(0.57,1.64)$ & 0.911 & & & \\
\hline Wood piled in yard & 1.00 & $(0.59,1.67)$ & 0.99 & & & \\
\hline Owns live stock & 1.2 & $(0.71,2)$ & 0.482 & & & \\
\hline Owns pets & 2.27 & $(1.19,4.35)$ & 0.013 & 3.33 & $(1.16,9.09)$ & 0.031 \\
\hline Has contact with pets & 0.67 & $(0.38,1.19)$ & 0.169 & & & \\
\hline Rodents spotted within house & 0.94 & $(0.55,1.64)$ & 0.836 & & & \\
\hline Rodents spotted around the house & 1.22 & $(0.41,3.7)$ & 0.721 & & & \\
\hline Presence of bushes within $5 \mathrm{~m}$ of the house & 2.27 & $(1.27,4.17)$ & 0.006 & 2.78 & $(1.11,7.69)$ & 0.033 \\
\hline Drying clothes on clothesline & 0.49 & $(0.23,1.04)$ & 0.064 & 0.31 & $(0.08,1.08)$ & 0.077 \\
\hline \multicolumn{7}{|l|}{ Child's Behavioural Factors } \\
\hline Usually partially dressed at home & 0.71 & $(0.4,1.26)$ & 0.241 & & & \\
\hline Wears footwear during play & 1.73 & $(0.72,4.16)$ & 0.218 & & & \\
\hline Plays outdoors usually & 0.38 & $(0.21,0.68)$ & 0.001 & 0.42 & $(0.14,1.23)$ & 0.115 \\
\hline Usually sits on furniture & 2.23 & $(1.02,4.86)$ & 0.043 & 0.45 & $(0.13,1.48)$ & 0.193 \\
\hline Usually sleeps on cot & 2.23 & $(1.3,3.81)$ & 0.004 & 1.53 & $(0.64,3.74)$ & 0.341 \\
\hline Sleep outside house - Yes & 0.99 & $(0.23,4.24)$ & 0.991 & & & \\
\hline Uses toilet & 1.51 & $(0.9,2.55)$ & 0.118 & & & \\
\hline
\end{tabular}


Table 2 Univariate and multivariate analysis on demographic, environmental and behavioural factors associated with acquisition of scrub typhus (Continued)

\begin{tabular}{|c|c|c|c|c|c|c|}
\hline \multirow[t]{2}{*}{ Variable } & \multicolumn{3}{|c|}{ Univariate Analysis } & \multicolumn{3}{|c|}{ Multivariate analysis } \\
\hline & $\overline{\mathrm{OR}}$ & $95 \% \mathrm{Cl}$ & $\overline{p \text {-value }}$ & $\overline{\mathrm{OR}}$ & $95 \% \mathrm{Cl}$ & $p$ \\
\hline Usually bathes after play & 1.92 & $(0.78,4.69)$ & 0.153 & & & \\
\hline Usually changes clothes before sleep & 1.39 & $(0.55,3.47)$ & 0.484 & & & \\
\hline Goes to school by vehicle & 4.38 & $(2.29,8.37)$ & $<0.001$ & 3.12 & $(1.40,7.12)$ & 0.006 \\
\hline Uses insect repellent & 1.92 & $(0.81,4.54)$ & 0.139 & & & \\
\hline
\end{tabular}

vicinity of the houses is associated with a 2.8 fold risk of acquiring scrub typhus and is a modifiable risk factor. Trombiculid mites have been isolated from poorly maintained kitchen gardens [23] and chigger density has been associated with grass density [10]. Keeping the immediate surroundings of the houses clean and free of vegetation may decrease the risk of acquisition of scrub typhus especially in children.

Of the behavioural risk factors, cooking outside the house which is practised in certain rural south Indian households is associated with an over 5 fold risk of acquisition of scrub typhus. It is likely that the storage and use of material used for cooking becomes a favourable environment for rodents and rodent density is linked with increased transmission of scrub typhus [2, 24]. In our study, owning a pet confers a 2.3 fold risk of acquiring scrub typhus possibly by increasing the chance of a child coming into contact with a chigger. The chiggers that transmit scrub typhus use many small mammals to complete their life cycle [11]. Dogs have been found to be infected with $O$. tsutsugamushi and could well be a reservoir in the transmission cycle of scrub typhus [25]. Although household pets have not been demonstrated to harbour mites transmitting scrub typhus, our study has demonstrated significant association of pets within the patients compared to controls. Study of pets especially dogs and the likelihood of their harbouring vectors such as mites that have a potential for transmitting scrub typhus may need further study. Dogs were the predominant pets



Fig. 2 Mite colonies in the ear of a rodent in our study too being present in $20.4 \%$ of the cases' houses. Travelling to school by a vehicle was also associated with a 4.4 fold increase in risk of scrub typhus in our study which is counter intuitive. It is possible that children travelling to school by vehicle travel a greater distance from their homes with an increased risk of exposure outside of their homes in addition to their own peri-domestic environment. Use of a clothesline to dry clothes showed a trend towards being protective against acquiring scrub typhus (OR 0.31; $\mathrm{p}$ 0.077). It is a common practice in rural areas for washed clothes to be dried on scrub vegetation, which can increase the risk of a chigger being transported on to the child's body when the clothing is being worn. Use of a clothesline to dry clothes may prevent such translocation of chiggers.

The vector survey done in our study by capturing rodents in the immediate vicinity of children who had scrub typhus disease has shown that $34.6 \%$ of houses where rodents were captured had the vector capable of transmitting scrub typhus. The estimated chigger ( $L$. deliense and S.ligula) index was well above the critical

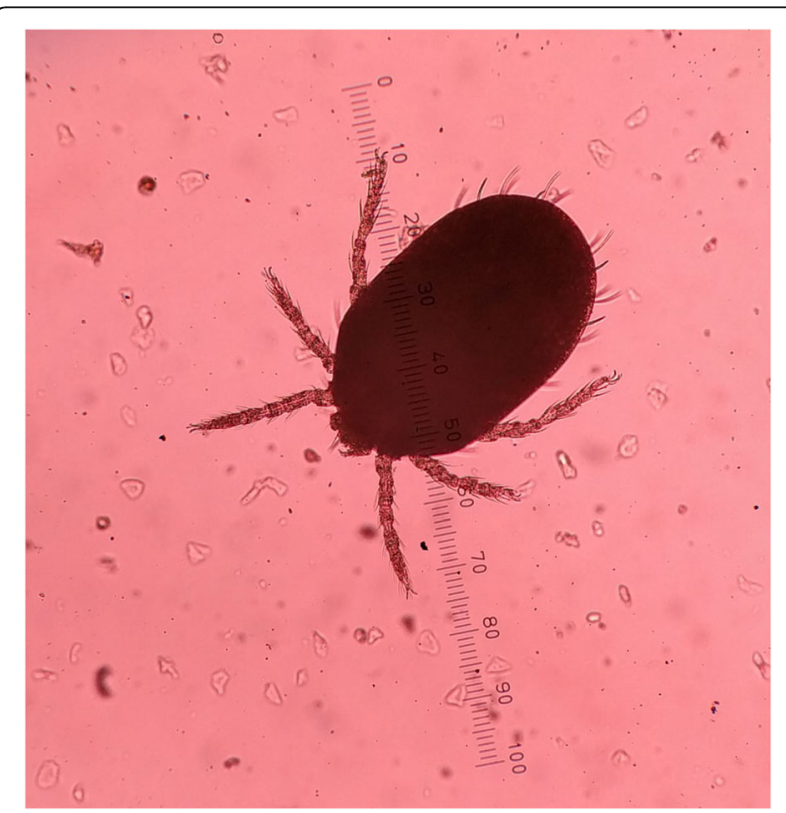

Fig. 3 Chigger of a trombiculid mite under microscope on a $1 \mathrm{~mm}$ scale 
Table 3 Distribution of mites isolated

\begin{tabular}{lll}
\hline Mites isolated & $\begin{array}{l}\text { Number of houses } \\
\text { where mites isolated(\%) }\end{array}$ & $\begin{array}{l}\text { Number of } \\
\text { mites isolated(\%) }\end{array}$ \\
\hline Leptotrombidium deliense & $9(34.6)$ & $85(33.5)$ \\
Leptotrombidium insigne & $19(73)$ & $139(54.7)$ \\
Schoengastia sp. & $2(7.7)$ & $2(0.8)$ \\
Schoengastiella ligula & $4(15.4)$ & $28(11)$ \\
No mites & $2(7.7)$ & 254 \\
Total & 26 & \\
\hline
\end{tabular}

level of 0.69 per rodent [21] in the villages surveyed indicating that the villages are receptive for scrub typhus transmission. Vector density is known to vary considerably depending on the season, vector species and rodent species [26, 27]. Many studies have trapped rodents in villages and found scrub typhus transmitting vectors, but have not been linked to cases of scrub typhus [10, 28, 29]. Our findings strengthen the argument that children could acquire scrub typhus close to their homes.

The main limitation of the study is the analysis with lesser number of controls than anticipated. Though the study recruited controls at a case control ratio of 1:2, 36 controls had to be excluded because of their seropositivity for scrub typhus. The seropositivity among the controls underlines that there is scrub typhus in these locations. The choice of parameters to compare between cases and controls were based on previous literature on similar studies and a field visit by the investigators. It is possible that some parameters may have been overlooked. The possible selection bias in the patients with higher SES seeking care at a tertiary centre and the absence of information on the health seeking behaviour among cases and controls is another limitation in the study. The vector survey identified the presence of chiggers capable of transmitting scrub typhus in the vicinity of the houses of children who had scrub typhus disease. Demonstration of $O$. tsutsugamushi in the chiggers would have strengthened the vector survey.

\section{Conclusions}

In conclusion, our study highlights risk factors for scrub typhus, some of which may be modifiable. A clean peridomestic environment free of vegetation, drying clothes on a clothesline and cooking indoors may decrease the risk of scrub typhus. Further studies are needed to determine the role of pets in the transmission of scrub typhus. With increase in the number and distribution of cases of scrub typhus in many countries, more studies are needed to evaluate the vector host interaction to institute public health measures for prevention.

\section{Abbreviations}

Cl: Confidence Interval; GIS: Geographic Information system; SES: Socioeconomic Status

\section{Acknowledgements}

The authors wish to acknowledge Mr.E. Prabhu who helped with the data entry, Mr. Sathyaseelan for trapping the rodents and isolating the mites, Ms. Vandana Kesarkar for performing the tests for scrub typhus, Mr. Paul Ebenezer and Ms. Esther Muzhumathy for performing the phlebotomies among control patients.

\section{Authors' contributions}

WR conceptualized, conducted the study and wrote the manuscript. GK and VPV were involved with interpretation of data, review and critical revision of the manuscript. SC identified the vectors and was involved with interpretation of data, review and critical revision of the manuscript. PS did the statistical analysis and was involved in the interpretation of data, review and critical revision of the manuscript. JJAP did the testing for diagnosis of scrub typhus and was involved with interpretation of the data, review and critical revision of the manuscript. JM was involved with the conceptualization of the study, interpretation of data, review and critical revision of the manuscript. All authors have read and approved the manuscript.

\section{Funding}

The whole study was funded by Wellcome Trust Training Grant Ref: 104021/ $\mathrm{Z} / 14 / \mathrm{Z}$. The fund provided for the conduct of the study including salaries for staff employed in the project, all.

laboratory testing related to the project and data analysis. The funders had no role in the study design, data collection, analysis, decision to publish or preparation of the manuscript.

\section{Availability of data and materials}

The data can be made available by the corresponding author. The email address of the corresponding author is winsleyrose@cmcvellore.ac.in

Ethics approval and consent to participate

Ethics committee approval was obtained from the Institutional Review Board (Registration Number: ECR/326/INST/TN/2013 issued under Rule 122D of the Drugs \& Cosmetics Rule 1945, Govt. of India) of Christian Medical College, Vellore to conduct the study. Institutional Animal Ethics Committee (IAEC) of the Christian Medical College, Vellore (Registration number: 88/PO/RcBi/SL/ 1999/CPCSEA registered with Committee for the Purpose of Control And Supervision of Experiments on Animals (CPCSEA), Ministry of Environment, Forests and Climate Change, Government of India) approval was also obtained for trapping of rodents to obtain mite chiggers. Written informed consent was obtained from a parent/guardian of all children who were enrolled in the study. Written assent was obtained from all children above the age of 8 years in addition to the parent/guardian consent. The rodents and shrews were captured using traps and anaesthetized to obtain mites from them. All rodents and shrews were released back in the same environment after obtaining the mites.

\section{Consent for publication}

Not applicable.

\section{Competing interests}

The authors declare that they have no competing interests. 


\section{Author details}

${ }^{1}$ Department of Pediatrics, Christian Medical College, Vellore, Tamil Nadu, India. 'Department of Gastrointestinal Sciences, Christian Medical College, Vellore, Tamil Nadu, India. ${ }^{3}$ Department of Health Research, Vector Control Research Centre, Pondicherry, India. ${ }^{4}$ Department of Biostatistics, Christian Medical College, Vellore, Tamil Nadu, India. ${ }^{5}$ Department of Microbiology, Christian Medical College, Vellore, Tamil Nadu, India. ${ }^{6}$ Present Address: Translational Health Science and Technology Institute, Faridabad, Haryana, India.

Received: 12 December 2018 Accepted: 18 July 2019

Published online: 26 July 2019

\section{References}

1. Watt G, Parola P. Scrub typhus and tropical rickettsioses. Curr Opin Infect Dis. 2003;16(5):429-36.

2. Ghorbani RP, Ghorbani AJ, Jain MK, Walker DH. A case of scrub typhus probably acquired in Africa. Clin Infect Dis Off Publ Infect Dis Soc Am. 1997; 25(6):1473-4.

3. Weitzel T, Dittrich S, López J, Phuklia W, Martinez-Valdebenito C, Velásquez K, et al. Endemic scrub typhus in South America. N Engl J Med. 2016; 375(10):954-61.

4. Izzard L, Fuller A, Blacksell SD, Paris DH, Richards AL, Aukkanit N, et al. Isolation of a novel Orientia species (O. chuto sp. nov.) from a patient infected in Dubai. J Clin Microbiol. 2010;48(12):4404-9.

5. Mathai E, Rolain JM, Verghese GM, Abraham OC, Mathai D, Mathai M, et al. Outbreak of scrub typhus in southern India during the cooler months. Ann N Y Acad Sci. 2003:990:359-64.

6. Rose W, Rajan RJ, Punnen A, Ghosh U. Distribution of eschar in pediatric scrub typhus. J Trop Pediatr. 2016;62(5):415-20.

7. Mittal M, Thangaraj JWV, Rose W, Verghese VP, Kumar CPG, Mittal M, et al. Scrub typhus as a cause of acute encephalitis syndrome, Gorakhpur, Uttar Pradesh, India. Emerg Infect Dis. 2017;23(8):1414-6.

8. Ogawa M, Hagiwara T, Kishimoto T, Shiga S, Yoshida Y, Furuya Y, et al. Scrub typhus in Japan: epidemiology and clinical features of cases reported in 1998. Am J Trop Med Hyg. 2002;67(2):162-5.

9. Panpanich R, Garner P. Antibiotics for treating scrub typhus. Cochrane Database Syst Rev. 2000;2:CD002150.

10. Lerdthusnee K, Khuntirat B, Leepitakrat W, Tanskul P, Monkanna T, Khlaimanee $\mathrm{N}$, et al. Scrub typhus: vector competence of Leptotrombidium chiangraiensis chiggers and transmission efficacy and isolation of Orientia tsutsugamushi. Ann N Y Acad Sci. 2003;990:25-35.

11. Traub R, Wisseman $C L$, Jones MR, O'Keefe JJ. The acquisition of rickettsia tsutsugamushi by chiggers (trombiculid mites) during the feeding process. Ann N Y Acad Sci. 1975;266:91-114.

12. Kim D-M, Park C-J, Lim S-C, Park K-H, Jang W-J, Lee S-H. Diagnosis of scrub typhus by immunohistochemical staining of Orientia tsutsugamushi in cutaneous lesions. Am J Clin Pathol. 2008:130(4):543-51.

13. Walker $\mathrm{DH}$. Scrub typhus — scientific neglect, ever-widening impact. N Engl J Med. 2016;375(10):913-5.

14. Burgdorfer W, Varma MG. Trans-stadial and transovarial development of disease agents in arthropods. Annu Rev Entomol. 1967;12:347-76.

15. Lyu Y, Tian L, Zhang L, Dou X, Wang X, Li W, et al. A Case-Control Study of Risk Factors Associated with Scrub Typhus Infection in Beijing, China. PLoS ONE. 2013;8(5) Available from: http://www.ncbi.nlm.nih.gov/pmc/articles/ PMC3653850/. [cited 2017 Aug 24].

16. Varghese GM, Raj D, Francis MR, Sarkar R, Trowbridge P, Muliyil J. Epidemiology \& risk factors of scrub typhus in South India. Indian J Med Res. 2016;144(1):76-81.

17. Kweon S-S, Choi J-S, Lim H-S, Kim J-R, Kim K-Y, Ryu S-Y, et al. A communitybased case-control study of behavioral factors associated with scrub typhus during the autumn epidemic season in South Korea. Am J Trop Med Hyg. 2009;80(3):442-6.

18. Sengupta M, Benjamin S, Prakash JA. Scrub typhus continues to be a threat in pregnancy. Int J Gynaecol Obstet Off Organ Int Fed Gynaecol Obstet. 2014;127(2):212.

19. Sharma R. Revised Kuppuswamy's socioeconomic status scale: explained and updated. Indian Pediatr. 2017;54(10):867-70.

20. Potdar VA, Hinge DD, Dakhave MR, Manchanda A, Jadhav N, Kulkarni PB, et al. Molecular detection and characterization of influenza " $C$ " viruses from western India. Infect Genet Evol J Mol Epidemiol Evol Genet Infect Dis. 2017 54:466-77.

21. Olson JG, Bourgeois AL, Fang RC. Population indices of chiggers (Leptotrombidium deliense) and incidence of scrub typhus in Chinese military personnel, Pescadores Islands of Taiwan, 1976-77. Trans R Soc Trop Med Hyg. 1982;76(1):85-8.

22. 4 Epidemiology-Scrub Thypus \& Geographical Distribution.p65 Geographical Distribution, Effect of Season \& Life Cycle of Scrub Typhus4. pdf [Internet]. [cited 2017 Aug 26]. Available from: http://www.jkscience.org/ archive/volume122/Geographical\%20Distribution,\%20Effect\%20of\%2 0Season\%20\&\%20Life\%20Cycle\%20of\%20Scrub\%20Typhus4.pdf

23. Mittal V, Gupta N, Bhattacharya D, Kumar K, Ichhpujani RL, Singh S, et al. Serological evidence of rickettsial infections in Delhi. Indian J Med Res. 2012;135(4):538-41.

24. Wei Y, Huang Y, Li X, Ma Y, Tao X, Wu X, et al. Climate variability, animal reservoir and transmission of scrub typhus in southern China. PLoS Negl Trop Dis. 2017;11(3):e0005447.

25. Nanayakkara DM, Rajapakse RPVJ, Wickramasinghe S, Kularatne SAM Serological evidence for exposure of dogs to rickettsia conorii, rickettsia typhi, and Orientia tsutsugamushi in Sri Lanka. Vector Borne Zoonotic Dis. 2013;13(8):545-9.

26. Lee SH, Lee Y-S, Lee IY, Lim JW, Shin H-K, Yu J-R, et al. Monthly occurrence of vectors and reservoir rodents of scrub typhus in an endemic area of Jeollanam-do, Korea. Korean J Parasitol. 2012;50(4):327-31.

27. Kuo C-C, Lee P-L, Chen C-H, Wang H-C. Surveillance of potential hosts and vectors of scrub typhus in Taiwan. Parasit Vectors. 2015;8 Available from: http:// www.ncbi.nlm.nih.gov/pmc/articles/PMC4666075/. [cited 2017 Aug 27].

28. Candasamy S, Ayyanar E, Paily K, Karthikeyan PA, Sundararajan A, Purushothaman J. Abundance \& distribution of trombiculid mites \& Orientia tsutsugamushi, the vectors \& pathogen of scrub typhus in rodents \& shrews collected from Puducherry \& Tamil Nadu, India. Indian J Med Res. 2016; 144(6):893-900.

29. Tilak R, Kunwar R, Wankhade UB, Tilak WW. Emergence of Schoengastiella ligula as the vector of scrub typhus outbreak in Darjeeling: has Leptotrombidium deliense been replaced? Indian J Public Health. 2011 55(2):92.

\section{Publisher's Note}

Springer Nature remains neutral with regard to jurisdictional claims in published maps and institutional affiliations.
Ready to submit your research? Choose BMC and benefit from:

- fast, convenient online submission

- thorough peer review by experienced researchers in your field

- rapid publication on acceptance

- support for research data, including large and complex data types

- gold Open Access which fosters wider collaboration and increased citations

- maximum visibility for your research: over $100 \mathrm{M}$ website views per year

At $\mathrm{BMC}$, research is always in progress.

Learn more biomedcentral.com/submissions 